\title{
THE CONTRIBUTION OF WORKPLACE SOCIAL INTERACTIONS TO EMPLOYEES RETENTION IN TRAVEL AND TOURISM INDUSTRY: A THEORETICAL CONSTRUCT
}

\author{
ABDULMALIK M ALHUSSAMI \\ Research Scholar, Department of Commerce, Aligarh Muslim University, Aligarh, Uttar Pradesh, India
}

\begin{abstract}
As the other organizations, travel and tourism enterprises don't aim at just recruiting high skilled, talented and productive workforce but also at retaining such employees despite this objective represents a challenge when we know that employees turnover rate is high in travel and tourism industry as found by many researches and studies conducted in several countries. The reason behind the high rate of employees turnover in travel and tourism industry is low remunerations, unsatisfactory work conditions, inflexible management system, long work hours, low job growth and advancement opportunities and so on, but the social interactions in work place among employees themselves and between employees and management, contribute to employees retention directly and through some mediator factors such as commitment, job satisfaction, low stress, and productivity that will be discussed in details in the current study.

KEYWORDS: Employees, Social Interactions, Retention, Travel \& Tourism
\end{abstract}

Received: Jun 01, 2017; Accepted: Jun 16, 2017; Published: Jul 19, 2017; Paper Id.: IJECRAUG20176

\section{INTRODUCTION}

Social interactions at workplace are a manifestation of social capital through which an employee can span structural holes and has an impact on performance and product innovation. It can be considered as a tool of providing solutions for work problems such as distrust, communication difficulties, and family infidelity (Bartolini, 2011). Employee retention as (Mita, 2014) defined is "a technique adopted by businesses to maintain an effective workforce and at the same time meet operational requirements". Thus, businesses seek effective, top performer, talented and integrated employees and not any employee and this can be possible through treating employees well at workplace as to adopt and energize social interactions among employees .Tourism is a social and economic phenomenon and labor-intensive industry depends on the service nature of tourist product and relies on social and humanistic interactions. Thus, tourism creates huge number of job opportunities in travel and tourism sector itself and in other sectors that provide tourism with production requirements. As a driver of employment growth and as one of the main driver of world economic, tourism totally contributed to employment in the other industries, indirectly, with $9.6 \%$ of total employment that reached in 2016 to 292,220,000 according to statistics of (WTTC, 2016). Tourism contribution to economic problem solution can also be reflected through creating job opportunities for women and youth in particularly. Nevertheless, turnover rate of employees in tourism sector is high in comparison to the other industries, what makes study of employees retention is inevitable. Tourism service stands on the foundation of social and human relations, so it must be prevailed among employees first, this from one side, and from the other side employees want to fulfill their social needs and to feel self fulfillment rather to have extra monetary rewards or to be provided with other good work condition, as has been proved by many studies and 
researches. Maslow theory indicated that employees have social needs and must be fulfilled and so, many studies relied on Maslow theory in personal development of employees, non-financial recognitions, human behavior, motivations and so on. Hence travel and tourism enterprises should pay more attention to employees' retention through enhancing intrinsic motivators, and communication, interpersonal skills and social interactions of employees are vital domains in this regard.

When tourist enterprises succeed in creating customer loyalty and retention, repeated customers/tourists who visit the intending tourist organization repeatedly feel happy as they meet their friend employees who remain working for the same organization due to successful retention policies. Thus, this friendship between employees and customers, contributes to employees retention, as customer loyalty is a main objective of any business organization and according which an organization ensure its continuous turnover. In same context, customer satisfaction influenced by the way of dealing and interaction of employees and particularly those in front line positions in travel and tourism enterprises (Robbins, 1994). Thus, when employees enjoy good social interaction within organization, they will be more able to create friendship with customers and create their loyalty and retention and in turn, this will make the management retain such employees.

In the discussion below, the contribution of social interactions of employees to employees 'retention through other variables/ mediators will be discussed in details.

\section{METHODOLOGY AND RATIONALE OF THE STUDY}

The current study focuses on social interactions of employees as a contributor to employees' retention rather than other factors as enhancing social and humanitarian interactions among employees and between employees and the management, is more applicable than adjusting pays system or work hours or conditions, besides the high rate of employees turnover in travel and tourism industry for the aforementioned reasons in the abstract, what indicates the importance of such study in providing some recommendations to be applicable by travel and tourism services providers to decrease turnover and increase employees retention.

\section{The Objectives of the Study Are}

- To find out whether social interactions of employees in workplace contribute to employees' retention.

- To provide some valuable recommendations that can be applicable by travel and tourism enterprises in enhancing social interactions of employees at workplace and in increasing employees' retention.

\section{REVIEW OF LITERATURE}

The high rate of employee turnover, due to reasons aforementioned, is not confined to a particular tourist organization or country, but it is a common issue (Mohsen, 2013). Hiring, promotion, rewards, compensation, recognition, corporate culture and organization mission and goals, are initiative practices that reduce employee turnover and increase employee retention as proved by (Moncars, 2009) in a study conducted on lodging properties in the United States. According to (Honore, 2009) employer should motivate their employees and provide them good work condition in order to make them more enthusiastic and more productive and then reduce employee turnover.

Employees working in hospitality and tourism industry are more likely to enter and exit from their tourism enterprises in comparison to other industries because of seasonality and hourly employment (Barron \& Anastasiadou, 2009; Milman \& Ricci, 2004; Taylor \& Finley, 2009) and in a similar way (Blank and Chiesa,2009) emphasized that because of seasonal nature of products and services of tourism and hospitality industry, enterprises/organizations are not 
always able to recruit, train and retain employees with the qualification they wish and around all the year. In the same context (Boella, 1998; Denvir \& Mc Mahon, 1992), stated that seasonal nature of the industry has an impact on the high rate of employee retention in tourism and hospitality, and a study conducted by (Neha Gupta, 2013) found that 55\% of respondents of targeted employees working in tourism industry are not having good social status as tourism jobs are not valued in the society and this is one of the reason behind high rate of employee turnover.

In contrast, (Price, 1994) argued that hotel industry itself makes the rate of employee turnover high through filling the vacancies by relying on external labor markets or what is known as the hourly, part time or seasonal workforce. Thus, other factors rather than seasonality have an impact on high employee turnover in hospitality and tourism industry such as: the high percentage of operational workers to the total workforce who seek promotion and leave the intending tourism enterprise to another ( Riely,1991), low training and development opportunity in tourism industry (Hogen, 1992), job dissatisfaction (Bonn and Forbringer,1992) and other determinants factor such as social status, compensations, working conditions and so on.

\section{DISCUSSIONS}

Unlike numerous studies that searched in the determinants of employee's retention aforementioned, the current study focuses on a factor that is not widely studied (social interactions of employees) despite its vital impact on employees retention in hospitality and tourism industry.

No doubt that social and humanitarian interactions of employees at workplace have a positive impact on employee health as a whole that can be reflected in high rate of satisfaction, low stress and high degree of enthusiasm and morale, and in this regard ( McEwen,1998) stated that social interactions of employees has an impact on physiological resourcefulness through enhancing and protection heart, neuroendocrine and immune systems, and physiological resourcefulness means that human body repair itself to easily deal and adopt with the challenges that might occur. Hence , employees who receive positive social interactions at workplace are more likely able to have high degree of self esteem and assertiveness and can work under any circumstances and work condition. The impact of social interaction of employees on employees retention can be representative in the friendship among employees that leads to team work and offering help whenever needed, but this impact can be more clear when discussing the mediator variables via/through which social interactions of employees at workplace influence employees retention as in below:

\section{EMPLOYEES' ORGANIZATIONAL COMMITMENT}

Employees' social/informal interactions and relationships might be positive or negative, so employees might offer help or harm each other and this help or harm will influence employees and organizations in number of ways and important outcomes and employees' organizational commitment is one of such important outcomes. Whenever an employee is having a centrality with positive interaction networks, valued and respected by the other employees for advice and friendship, such employee should have an impact on the other employees' attitudes and intentions of attachment (Kahn, 1998).

'When employees demonstrate a desire of offering advices and voluntary helps and creating friendships with each other, through social/ informal interactions networks, such interactions will enhance their emotional commitment and then organizational commitment as a whole. In contrast, when such interactions are negative, it seems to have a negative impact on employees attitudes of commitment or in other word, it more likely leads to withdrawal and turnover. Hence, the studies 
should focus also on negatives ties and evaluate interactions networks from the context of employees have negative ties because such employees, according to (Peeters \& Czapinski, 1990), are more aware of their social standing at workplace. Based on what has been aforementioned, employees with a high degree of commitment are distinguished by strong belongingness and loyalty and then they are less likely to be involved in absenteeism and turnover (Golden and Veiga, 2008). Thus, it can be said that social interactions of employees' influences employees' organizational commitment and via (O.C) influences employees’ retention.

A famous survey conducted in The United State (Gallup survey), revealed that $51 \%$ of employees who reoprted that they have best friend at work also reported that they work wilt full passion and profoundly attached to their company and $71 \%$ of those who reported that they have best friend at work, reported also that they have intention to remain work for their company compared with $51 \%$ of those who reported have no best friend at work (Rath, 2006).

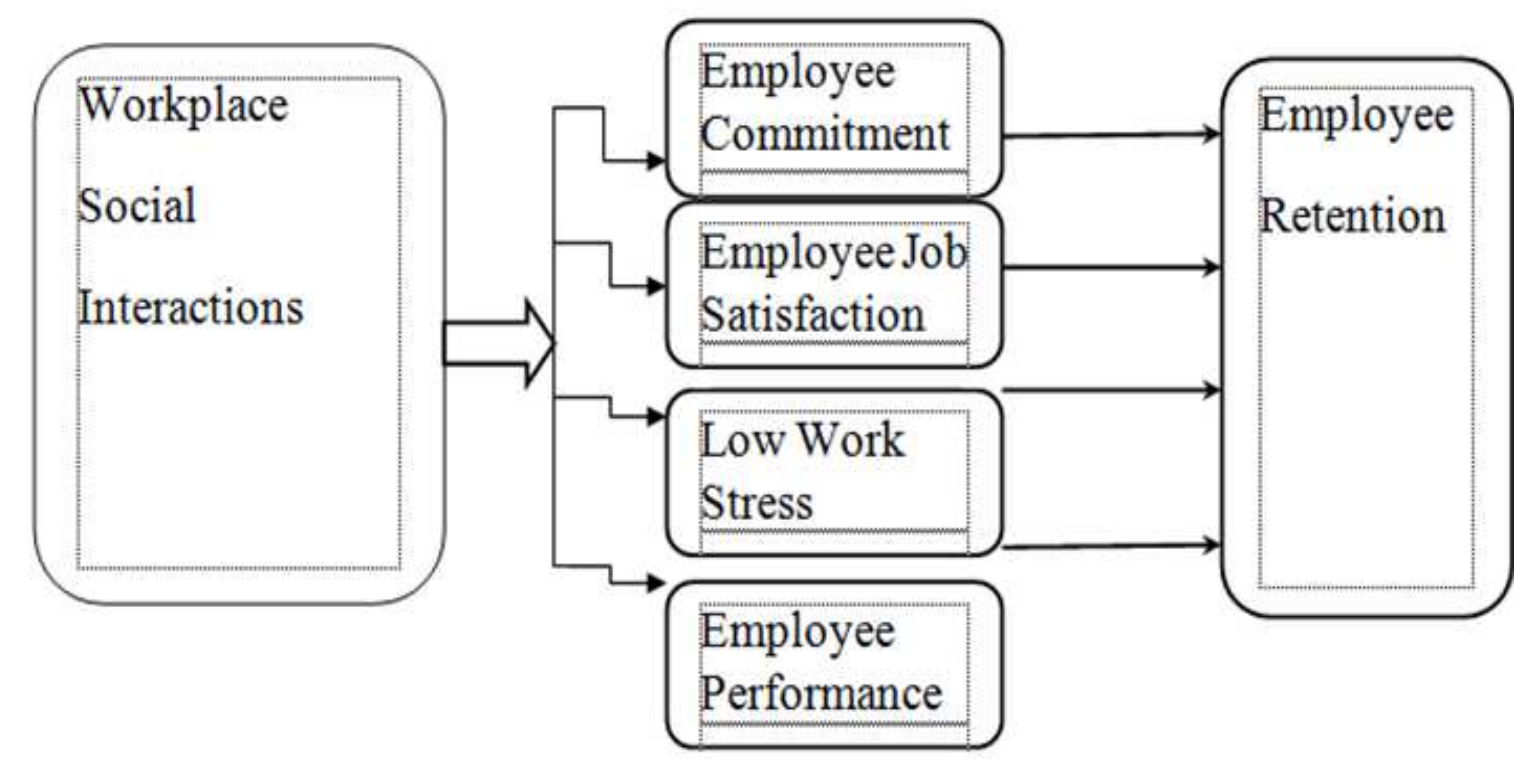

Figure 1: Research Model

\section{Source: Prepared by the Researcher}

\section{EMPLOYEES’ JOB SATISFACTION}

Social interactions of employees in workplace enhance trust in both co-workers and leadership, promote the quality of teamwork and collaboration and influence employees perception on work condition, so it can be said that social relations leads to quality of life at workplace and increase level of employees job satisfaction (Requena, F,2003).

As job satisfaction is a pleasurable state, social interactions and friendships based on love, emotion, aspiration, trust etc., impact employees' job satisfaction and some other domains of employees work attitudes such as commitment, engagement and employees' perception about the organizational support(Zagenczyk et al, 2010). Furthermore, social interactions/interpersonal interactions or contact is considered as one of extrinsic factors effecting employees' job satisfaction in the famous motivators-hygiene theory that leads to job dissatisfaction when it is poor or there is lack in it whereas when it is nurtured and positive it leads to job satisfaction (Herzberg, n.d.). Employees might have negative work attitudes (job satisfaction, commitment, engagement so on but in case of existence of positive social relationships among colleagues, such negative attitudes can be mitigated (Olshfski,2008).Highly job satisfied employees, through involvement 
practices as (Vera, 2001) discussed, report low degree of turnover. Similarly, (Rajendran \& Chandramohan, 2010) stated that the job satisfaction is not only important as it influences employees' efficiency but also as it influences employee's behaviors at workplace such as accidents, absenteeism, stress and turnover. Thus, social interactions of employees in travel and tourism cannot be underestimated as so long as it influences employees' job satisfaction and the last play a vital role in creating satisfaction of customer/tourists who come back to their homes with nothing except the memory.

\section{LOW WORK STRESS}

Many employees, more likely, experience a work stress due to long working hours, absence of the matching between employees' roles and responsibilities from one side and employees profiles (knowledge, skills, competencies and qualifications) from the other side and roles ambiguity and conflict, but when stress has mental or emotional aspects it demonstrates the significant contribution of employees social interactions to employees work stress; when social interactions reported to be positive, it decrease employees' work stress. Hence, low stress decreases employees' intentions of quit and turnover. Employees may be decide to leave their firm/companies they are working for and search for another companies/ firms where, as they think, they will be happier and no such work stresses (Shim, 2010).Thus, work stress influences employees' retention/ turnover. work stress factors differ from each other up-to the extent that make the definition of work stress difficult but the psychological domain of work stress cannot be inevitable as work stress according to (Beer ,1976), is the situation that enforces employee to deviate from normal functioning due to his/her psychological and/or physiological changes. Based on what aforementioned, social interactions, no doubt, influence work stress and employees' retention.(Fine,1986) stated that workplace friendship helps employees to accomplished their works, increase communication, cooperation and energy, and reduces work stress. Through an empirical study conducted on two organizations in Japan by (Eisuke Ono, et.al,, 2011), it had been proved that social interactions is significantly influence work stress, indicating that social interactions in the targeted organizations reported a quantified work stress pointing out that employees who experience a large amount of social interactions and face to face contact time, are intended to have low work stress.

Work stress comes in different forms/types : physical, emotional/mental and behavioral, created by some interventions such as: long working hours, unsuitable work conditions, incompatibility between roles and profiles of employees, unsatisfactory compensation and recognition system, inflexible organizational culture/ climate, poor personal characteristic state, low social state, poor work interactions and relations and so on, but the informal/ social interactions, remain a main determinant of work stress and through it a main contributor to employees retention in travel and tourism industry based on the communicative nature of tourist services and as tourism is a contemporary tool of coexistence and social and humanistic communication among nations, so how will an employee in travel and tourism industry be a good human communicator with consumers/tourists if he/she is not experiencing sufficient amount of positive social interactions and face to face contact time ?!. Hence, when employee is not able to fulfill customer/ tourist expectations and to create customer satisfaction that is taken as a parameter of service quality and employee performance appraisal, this will add ultra-stress on the intending employee.

Work stress more occurs among newly hired and young employees as they more aggressive and sensitive so they are more likely to be vulnerable to work stress (Qianqian Du et.al, 2009).Moreover, new hired young employees, as they patiently wait for tenure, fear layout and this will pose another issue when we know that tourism industry recruits young employees more than any other industry. Thus, treating employees well through promoting positive social interactions at 
workplace will mitigate and provide effective solutions for work stress issue in industry of communication among nation; the travel and tourism industry.

\section{EMPLOYEE PERFORMANCE}

When informal interactions and emotional relations prevail at workplace among employees, it will be conducive to cooperative work and in return will enhance employees performance in both quality and quantity as such interactions increase the harmonious emotions and strengthen home identity workplace atmosphere that burn employees enthusiasm and motivate them toward accomplishments making.

Such social interactions occur at workplace as a logical result of human being; the employee is social by his/her nature and has social needs to be fulfilled according to Maslow theory of needs. Thus, employees interact socially and emotionally with each other as they are directed by the affiliation and attachment motive. Accordingly, social interactions as a form of social capital and trust enhances the possibility of interunit exchange of resources and this in turn significantly effects on product innovation (Tsai \& Ghosal, 1998). Through interunit exchange of employees, an employee becomes able to span structural holes and this ability impacts his/her performance and definitely this performance will employee retention as any organization seeks retaining the talented and top performer employees.

Fore shedding more light on our present issue, it can be said that an employee who join hand cooperatively with other employees and interact positively with them to help and/or advise them how to do what they cannot in isolation, help in achieving both organizational and individual goals whereas an employee who keeps distance with coworkers and interacts with jealousy, hatred and backbiting will creates conflict and negatively contribute to performance and to individual and organizational goals achieving. In tourism industry as the number of employees work in front line positions and directly interact with tourists is large, tourism businesses should pay more attention to reinforcing positive social interactions among employees in order to create the love, trust, and cooperation atmosphere at workplace in the way that enable employees of positive interaction with customer/ tourists, principally any mistake in employee performance cannot be blocked.

\section{CONCLUSIONS}

No doubt that social interactions at workplace cannot be underestimate, but in travel and tourism industry, it plays a vital role in effecting employees' attitudes and work related outcomes as it enhances respect, love, trust, security, feelings of belongingness, team spirit and home atmosphere among employees at workplace and such values create employee commitment and job satisfaction, reduce work stress and help employees to accomplish their tasks and responsibilities and all these work related attitudes will lead to employees retention as businesses seek more productive, more committed, and more integrated employees.

As number of hours spent at workplace in travel and tourism industry are long in comparison to other industries, tourist businesses should energize and patronage friendship and social interactions among employees and between employees and management.

Through reviewing the important studies aforementioned, it becomes clearer that social interactions at workplace contribute to employee retention through some work related outcomes such those subjected to study ( employee organizational commitment, employee job satisfaction, work stress, and employee performance). 
The present study, accordingly, provides some recommendations that can be applicable by travel and tourism enterprises to enhance social interactions of employees at workplace and then increase employees' retention as: allowing employees to literally move among department in order to enlarge their knowledge base and fulfill their social needs, adopting social media and online social networking use among employees and between employees and management, encouraging employees to create friendships at workplace, and promoting spirit of cooperation, trust, love and mutual respect among employees, which, in turn, will leads to employee retention.

Finally, for better results, the negative impact of social interactions at workplace should not be neglected, but should go along with the positive impacts. In the present study, positive social interactions lead to commitment, job satisfaction, low work stress, and employee's performance and vice versa.

\section{REFERENCES}

1. Barron, P. \& Anastasiadou, C. (2009). "Student part-time employment: Implications, challenges and opportunities for higher education”, International Journal of Contemporary Hospitality Management. 21(2), 140-153.

2. Bartolini, S., 2011). "Sociability predicts happiness in nations: Evidence from macro and micro data. In S. Bartolini (Ed.), Policies for Happiness", Oxford: Oxford University Press.

3. Beehr, T.A., (1976). "Perceived Situational Moderators of the Relationship between Subjective

4. Role Ambiguity and Role Strain", Journal of Applied Psychology, issue 61, pp. 35-40.

5. Blanke, J. \& Chiesa, T. (Eds.). (2009), "The Travel and tourism competitiveness report: Managing in a time of turbulence", World Economic Forum, Davos, p. 525. Retrieved from: www.weforum.org/reports/global-competitiveness-report-2009-2010.

6. Boella, M.J. (1988)., "Human Resources Management in the Hotel and Catering industry", London: Pitman.

7. Bonn, M.A. And For bringer, L.R. (1992)., "Reducing Turnover in the Hospitality Industry: An Overview of Recruitment, Selection and Retention", International Journal of Hospitality.

8. Eisuke Ono, Takayuki Nozawa, Taiki Ogata, Masanari Motohashi, Naoki Higo, Tetsuro Kobayashi, Kunihiro Ishikawa, Koji Ara, Kazuo Yano, and Yoshihiro Miyake, 2001). "Relationship between Social Interaction and Mental Health", SI International 2011, 978-1-4577-1524-2/11.

9. Fine, G. ,1986). "Friendship in the workplace. In V.J. Derlega, and B.A. Winstead (Eds.). Friendship and social interaction (pp. 185-206). New York, NY: Springer-Verlag.

10. Golden TD, Veiga JF (2008). "The impact of superior-subordinate relationships on the commitment, job satisfaction, and performance of virtual workers", Leadership. Q., 19, pp. 77-88.

11. Gupta, Neha, ( 2013), "A Study of Employee Retention with Special Reference to Indian Tourism Industry”, European academic research, VOL. I, issue 6, September 2013.

12. Hogan, J.J. (1992)., "Turnover and What to do about it", Cornell Restaurant and Hotel Administration Quarterly, issue 33 , vol,pp 40-5.

13. Honore, J. (2009), 'Employee Motivation', Consortium Journal of Hospitality \& Tourism, 14(1), 63-75.

14. Kahn, W.A.(1998). "Relational system sat work. In L. L .Cummings \& B. M. Staw (Eds.)" ,Researchinorganizationalbehavior,Vol.20,pp.39-76, Greenwich, CT: JAI Press.

15. McEwen, B. S.( 1998)., "Protective and damaging effects of stress mediators", New England Journal of Medicine, 338: 171- 
16. Milman, A. \& Ricci, P. (2004), "Predicting job retention of hourly employees in the lodging industry”, Journal of Hospitality and Tourism Management. 11(1), 28-41.

17. Mita, M., Aarti K. and Ravneeta, D. , (2014) "Study on Employee Retention and Commitment" , International Journal of Advance Research in Computer Science and Management Studies, 2, 154-164.

18. Mohsin, A., Lengler, J. \& Kumar, B. (2013), "Exploring the antecedents of intentions to leave the job: the case of luxury hotel staff", International Journal of Hospitality Management, 35

19. Moncarz, E., Zhao, J., \& Kay, C. (2009), 'An exploratory study of US lodging properties: organizational practices on employee turnover and retention', International Journal of Contemporary Hospitality Management, 21(4), 437-458.

20. Peeters, G., \& Czapinski, J.(1990). "Positive-negative symmetry inevaluations: The distinction between affective and informational negativity effects", European Review of Social Psychology, issue 1,pp.33-60.

21. Price, L. (1994)., “Poor Personal practice in the Hotel and catering Industry: Does it Matter?” Human Resource Management Journal issue4, vol4, pp. 44-62.

Personnel Today, issue 30, vol 4 .. Griffeth, R.W. (1995). “The opportunity for friendship in the workplace: An underexplored construct” , Journal of Business and Psychology, 10, 141-154.

24. Requena, F.(2003). "Social capital, satisfaction and quality of life in the workplace", Social indicators research, issue 61, vol 3, pp, 331-360.

25. Riley, M. (1991)., "An Analysis of Hotel Labor Markets"' In cooper C.P. (ed.) Progress in Tourism, Recreation and Hospitality Management. London: Belhaven, pp. 232-46.

26. Robbins, (1994), “organizational behavior”, printec hall, pp, 183-189.

27. Shim, M. , 2010). “Factors influencing child welfare employee's turnover: focusing on

28.

Organizational culture and climate”, Children and Youth Services Review. 32(6), $847-856$

29. Song, S., Olshfski (2008). "Friends at work: A comparative study of work attitudes in Seoul City Government and New Jersey State Government”, Administration and Society, issue 40, vol 2, pp.147-169.

30. Taylor, M. \& Finley, D. (2009), “Acculturation, assimilation, and retention of international workers in resorts”, International Journal of Contemporary Hospitality Management, 22(5), 681-692.

31 .

Tsai, W., \& Ghosal, S., 1998). "Social capital and value creation: The role of intrafirm networks", Academy of Management Journal, 41(4), 464-476.

32. Vera C, R.J. (2001), "The correlation of employee involvement and turnover", Unpublished M. Sc. Thesis.

33. WORLD Travel and Tourism Council report, 2016.

34. Zagenczyk, T.J., Scott K.D, Gibney, R., Murrel, A.J., Thatcher, J.B. (2010). "Social influence and perceived organizational support: A social networks analysis", Organizational Behavior and Human Decision, issue 111,vol 2,pp. 127-138. 